\section{Schedule-induced drinking as a function of interpellet interval}

\author{
J. D. KEEHN and V. A. COLOTLA \\ York University and Addiction Research Foundation, Toronto, Ont., Canada
}

Two white rats reinforced with 45 -mg Noyes pellets on fixed-interval schedules from $15 \mathrm{sec}$ to $5 \mathrm{~min}$ exhibited a bitonic relationship between level of polydipsia and fixed-interval value. This relationship depended on three characteristics of drinking: frequency, distribution, and duration. At shorter FIs drinks occurred frequently shortly after reinforcement, and drink durations and frequencies varied directly with interval length. At longer intervals, drinking seldom occurred after reinforcement but was more frequent later in the interval. Late drinks were usually brief.

When he first described schedule-induced polydipsia, Falk (1961) reported a typical pattern of postpellet drinking behavior. This observation has since been confirmed many times (e.g., Keehn, 1970; Segal, 1969; Stein, 1964). Falk (1966) has also reported an increase in level of polydipsia as interpellet intervals increase, up to a point. This finding has also been confirmed (Burks, 1970 Colotla, Keehn, \& Gardner, 1970) and seems to depend more on increased drink durations in longer interpellet intervals than on increased frequencies of postpellet drinks (Colotla et al, 1970). However, when interpellet intervals are long enough (e.g., $3 \mathrm{~min}$ or more) fluid consumption decreases back to normal levels (Falk, 1966; Hawkins, Everett, Githens, \& Schrot, 1970). It remains to see how drink durations and postpellet drink frequencies are affected by long interpellet intervals (cf. Segal, Oden, \& Deadwyler, 1965).

\section{SUBJECTS}

Two 300-day-old male albino rats were used. They had previously taken part in studies of polydipsia with and without drugs, but had not been used for experimentation for over a month before the present study. They were maintained at $85 \%$ of their free-feeding weights at 100 days of age and were housed in individual cages with tap water always available. APPARATUS

A standard Grason-Stadler two-bar rat chamber, Type E3125B, was used. The left-hand bar was removed, and its opening covered with a metal plate mounted flush with the wall. A weight of $20 \mathrm{~g}$ on the remaining bar served to activate relay programming and recording equipment. A water bottle was attached to the chamber door such that a $S$ could lick at its glass outlet tube through a hole $25 \mathrm{~mm}$ above floor level and $90 \mathrm{~mm}$ from the wall containing the response bar and food magazine. Licks at this tube were registered on a Gerbrands cumulative recorder via a Grason-Stadler drinkometer. The experimental chamber was housed in a sound-attenuating ventilated chest supplied with a viewing window. PROCEDURE

Because the animals were experienced, no pretraining was necessary. Experimental sessions were run daily, except at weekends and occasional holidays, and lasted until S obtained 25 reinforcers $(100$ in Sessions 54-65) scheduled as follows: FI $1 \mathrm{~min}$ (Sessions 1-15), FI $5 \mathrm{~min}$ (Sessions $16-30$ ), FI $1 \mathrm{~min}$ (Sessions 31.33 ), FI $2 \mathrm{~min}$ (Sessions 34.43 ), F I $3 \mathrm{~min}$ (Sessions 44-53), FI $15 \mathrm{sec}$ (Sessions 54-65). Cumulative licking records and water consumption were logged daily.

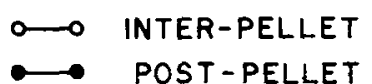

554

S 65

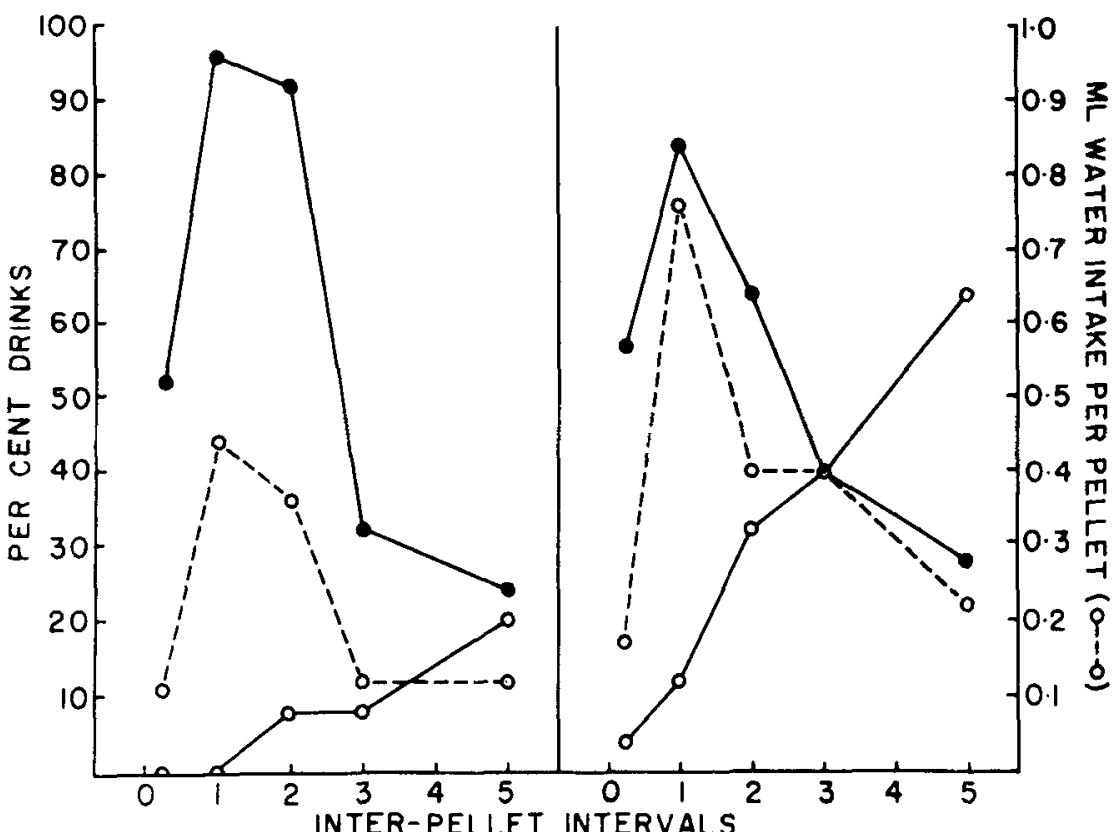

Fig. 1. Median fluid intakes per pellet and median percent of interpellet intervals in which drinking occurred within 10 sec of reinforcement (postpellet drinks) and at least 10 sec after reinforcement or drinking (interpellet drinks) over the final three sessions of each FI schedule. Only one postpellet and/or one interpellet drink was scorable per interval. 


$$
\text { S } 54
$$

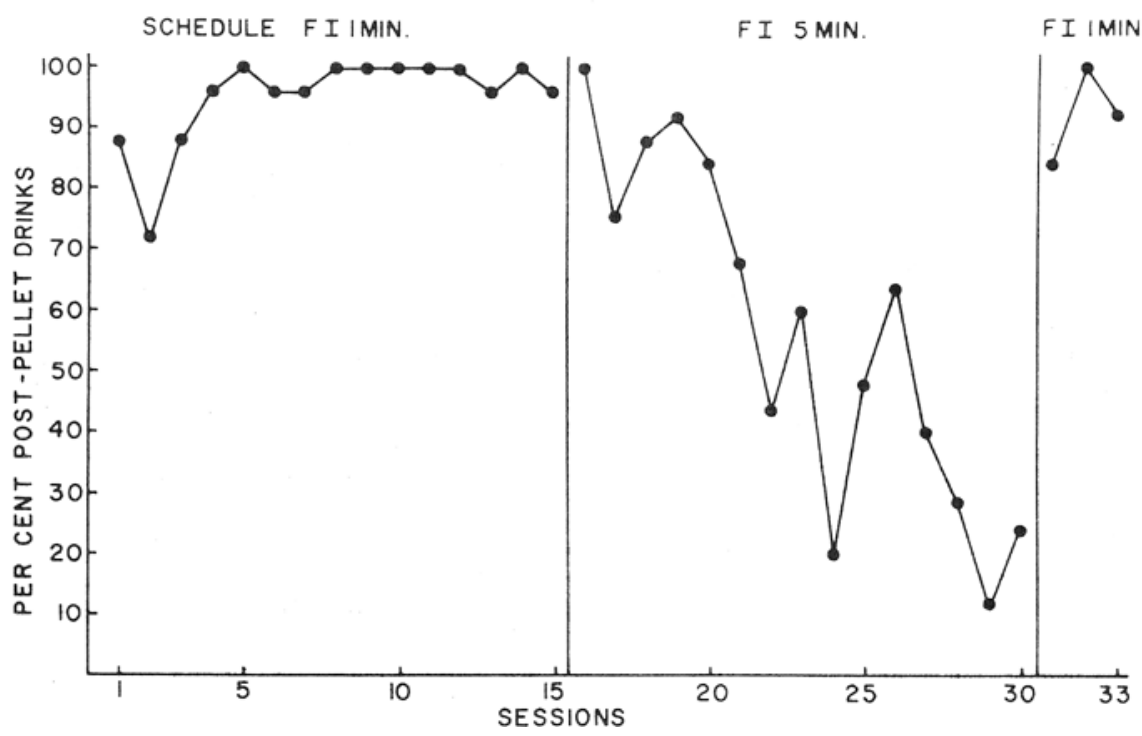

Fig. 2. Percent of intervals in which postpellet drinks occurred on successive sessions under the designated reinforcement schedules. Data of Animal S65 were similar.

reinforcers. Postpellet drinks rarely lasted for the whole of the 1-min interval, but it can easily be seen that drink durations were longer with the FI 1-min than with the FI 15-sec schedule of reinforcement.

Many fewer postpellet drinks and many more interpellet drinks occurred when reinforcers were scheduled at 5-min intervals. Only six examples of postpellet drinks with this schedule appear in the figure-following the 2nd, 3rd, 4th, 5th, 6th, and 11th pellets. Most of these were of relatively long duration, in contrast to the numerous interpellet drinks, which were usually of short duration and which often occurred as short bursts of licks interrupted by barpresses towards the end of the fixed interreinforcement interval.

\section{DISCUSSION}

The bitonic relationship between level of schedule-induced polydipsia and interreinforcement interval duration appears to depend mainly upon two different behavioral characteristics controlled by the reinforcement schedule: (1) The increasing level of fluid consumption as interpellet interval increases results from an increase in postpellet drink durations (Colotla et al, 1970); (2) the decreasing level of fluid consumption when interpellet intervals exceed some value stems from a decline in postpellet drink frequencies. In both cases complications arise. In the present study, frequencies as well as durations of postpellet drinks increased substantially between 15and 60-sec interreinforcement intervals, and interpellet drink frequencies increased as postpellet drink frequencies declined in the longer interreinforcement intervals. It is doubtful, though, if these complications much affected the overall shape of the curve relating fluid intake to interreinforcement interval.

Drink durations and drink frequencies could be measures of two different types of drinking that contribute to the total amount of fluid FI 5 min. Data of Animal S54 were similar. consumed. Falk's (1961) original report of schedule-induced polydipsia referred only to drinks that occurred "shortly after a pellet," i.e., postpellet drinking. Since then other drinking by intermittently fed rats has also been reported. Thus, Segal (1969) has described some schedule-induced drinking as operant, i.e., occurring before rather than after reinforcement, Rosenblith (1970) has reported "a second type of drinking" that occurs with second-order reinforcement schedules, and Keehn, Colotla, \& Beaton (1970) have distinguished between postpellet and interpellet drinking, the latter depending on palatability. In all these cases, the second type of drinking has differed from the first in occurring more remotely in time from preceding feeding or reinforcing events and in being less orderly in terms of duration and frequency of occurrence (Keehn \& Colotla, in press; Keehn, Colotla, \& Beaton, 1970).

It is, however, questionable whether there is more than one kind of schedule-induced drinking or whether the differences are merely stages of transition to a terminal (unstable) pattern of behaving (cf. Keehn, 1970) that is maintained by the proximity of the cessation of drinking to reinforcement (operant drinking, Segal, 1969) and initiated by the onset o f non re i n o r c m e n t (extinction-induced drinking, Keehn \& Colotla, 1970). We have been able to control schedule-induced drink durations by way of

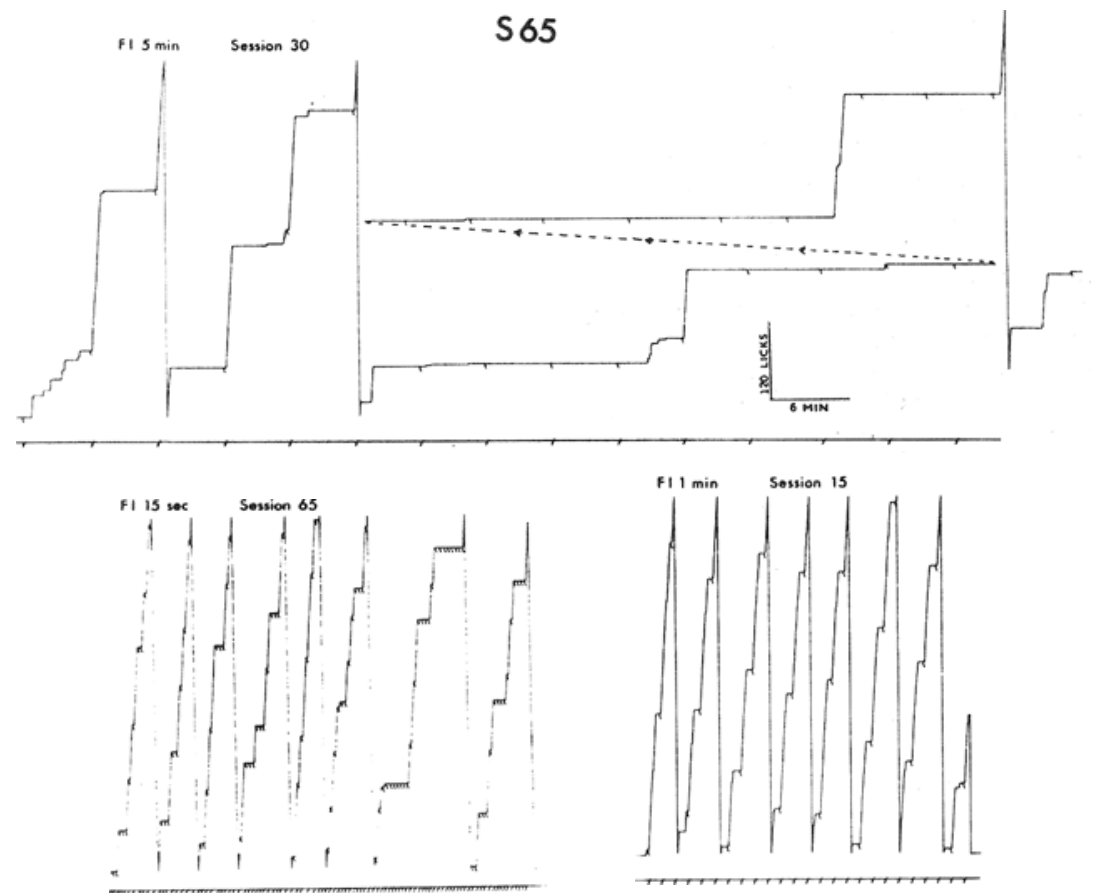

Fig. 3. Cumulative licking records of 565 under FI $15 \mathrm{sec}$, FI $1 \mathrm{~min}$, and 
interreinforcement intervals (Colotla et al, 1970), but this means of control is limited to intervals that maintain high frequencies of postpellet drinking, i.e., those intervals in which reinforcement is available shortly after the cessation of drinking.

\section{REFERENCES}

BURKS, C. D. Schedule-induced polydipsia: Are response-dependent schedules a limiting condition? Journal of the Experimental Analysis of Behavior, 1970. $13,351-358$.

COLOTLA, V. A., KEEHN, J. D., \& G ARDNER, L. L. Control of schedule-induced drink durations by interpellet intervals. Psychonomic Science, 1970, 21, 137-139.

FALK, J. L. Production of polydipsia in normal rats by an intermittent food schedule. Science, 1961, 133, 195-196.

FALK, J. L. Schedule-induced polydipsia as a function of fixed-interval length. Journal of the Experimental Analysis of Behavior, $1966,9,37-39$.

HAWKINS, J. D., EVERETT, P. B., GITHENS, S. H., \& SCHROT, J. F. Adjunctive drinking: A functional analysis of water and alcohol ingestion. In
Schedule. induced and schedule-dependent phenomena. Vol. 1. Toronto: Addiction Research Foundation 1970. Pp. 113-136.

KEEHN, J. D. Schedule-induced licking and polydipsia. Psychological Reports, 1970 , $26,155-161$.

KEEHN, J. D., \& COLOTLA, V. A Prediction and control of schedule-induced drink durations. Psychonomic Science, 1970, 21, 147-148. KEEHN, J. D., COLOTLA, V. A., \& BEATON, J. $\ddot{M}$. Palatability as a factor in the duration and pattern of schedule-induced drinking. Psychological Record, in press.

ROSENBLITH, J. Z. Polydipsia induced in the rat by a second-order schedule. Journal of the Experimental Analysis of Behavior, 1970, 14, 139-144.

SEGAL, E. F. Transformation of polydipsic drinking into operant drinking: A paradigm? Psychonomic Science, 1969, $16,133-135$.

SEGAL, E. F., ODEN, D. L., \& DEADWYLER, S. A. Determinants of polydipsia: IV. Free-reinforcement schedules. Psychonomic Science, 1965, 3, 11-12.

STEIN, L. Excessive drinking in the rat: Superstition or thirst? Journal of Comparative \& Physiological Psychology $1964,58,237-242$.

inordinate amount of parental beatings. The children, in turn, would aggress toward their peers with such intensity that it was often the cause of law-enforcement difficulties and consequent referral to the Juvenile Court. In an attempt to validate experimentally this clinical observation and to extend the nature of the variables affecting pain-elicited fighting, young rats were shocked in the presence of another peer, their own natural mother (NM), or a surrogate mother (SM). It was hypothesized that young rats paired with their NMs would exhibit less aggression than those paired with SMs. It was further expected that the number of encounters between littermates would be greater than that exhibited in the presence of NM or SM.

\section{SUBJECTS}

The Ss were 20 male and 22 female Sprague-Dawley albino rats. There were seven litter groups born within the laboratory: four were all male, one was all female, and two were mixed, i.e., half male and half female. All Ss were weaned at 34 days of age. The seven NMs, weighing on the average $288 \mathrm{~g}$, were matched with seven SMs who had a mean weight of $295 \mathrm{~g}$. Half of all the peer groups were tested in the presence of NM and the other half with SM.

\section{APPARATUS}

The experimental chamber measured $10 \times 12 \times 9$ in. Two sides were of sheet metal, while the remaining sides and ceiling were made of clear Plexiglas. The grid floor consisted of 20 steel rods, $1 / 8$ in. in diam and spaced .5 in. apart. A small 15-W lamp provided the sole source of illumination in the darkened testing room. Auditory masking was provided by a white-noise generator. Scrambled shock was delivered by a Lafayette constant-current stimulator. Shock intensity was $1.50 \mathrm{~mA}$ for the first 3 days and $1.75 \mathrm{~mA}$ for the remainder of testing.

Fairfield University, Fairfield, Conn. 06430

In a shock-elicited fighting situation, young rats tested between 34 and 47 days of age exhibited significantly more attacks when paired with a littermate as compared with a natural or a surrogate mother. Attack suppression occurred during the initial test sessions only for the natural mother paired with her young when contrasted with the number of encounters between the young and the surrogate mother.

If rats are shocked together, consistent attack behavior is observed. This pain-aggression syndrome was originally conceived as reflexive in character with fighting considered as an unconditional response to pain (Ulrich \& Azrin, 1962). Even paired housing over several weeks did not alter the fighting rate, although this latter position has been challenged

* Requests for reprints should be addressed to John J. Boitano.
(Roberts \& Larson, 1967). Furthermore, fighting is monotonically related to age. From 33 days of age to 43 days, fighting probability (i.e., number of attacks/total number of shocks) increased from .27 to .41 (Hutchinson, Ulrich, \& Azrin, 1965).

It was observed by one of us (RPJ) in the Juvenile Court of Bridgeport that behavior-problem children were frequently the recipients of an

\section{PROCEDURE}

On the day after weaning, each young was paired with either a $\mathrm{NM}$ or SM and with another young from the same litter group. This resulted in three pairings per litter-test group, i.e., young No. 1 was shocked with young No. 2, and both were independently shocked with the mother. The order of testing was balanced throughout the experiment and was identical for all litter groups.

A trial consisted of 30 shock presentations. Since each $\mathrm{S}$ was tested twice per day, a total of 60 shocks for 12 consecutive days was administered. The intershock interval was $8 \mathrm{sec}$, while shock duration was 1 sec. The intertrial interval was $60 \mathrm{sec}$. 